\title{
1.1 Explanation of Directory Entries / Erläuterung der Verzeichnis- einträge / Explication des entrées
}

\section{INSTITUTION OF EDUCATION / AUSBILDUNGSINSTITUTION / L'INSTITUTION DE FORMATION}

$\begin{array}{llll}01 & \text { Place of studies } & \text { Studienort } & \text { Localisation } \\ 02 & \text { Contact person } & \text { Ansprechpartner } & \text { Personne à contacter } \\ 03 & \text { Staff } & \text { Kollegium } & \text { Personnel } \\ 04 & \text { Number of students } & \text { Zahl der Studierenden } & \text { Nombre d'étudiants } \\ 05 & \text { Main fields of research } & \text { Forschungsschwerpunkte } & \begin{array}{l}\text { Principaux domaines } \\ \text { de recherche }\end{array} \\ 06 & \text { References } & \text { Quellen, Informationen } & \begin{array}{l}\text { Sources, } \\ \text { documentaires }\end{array} \\ 07 & \text { Graduation } & \text { Studienabschluß } & \text { Diplôme } \\ ! & \text { Notes } & \text { Hinweis } & \text { Notes }\end{array}$

\section{ACADEMIC SUBJECTS / STUDIENFÄCHER / DISCIPLINES}

07

08

09

10

11

12

13

14

15 Practical studies

16 Exams

17 Study duration

18 Professions of graduates

! Notes
Studienabschluß

Ausbildungsebene

Zulassung

Bewerbungsfrist

Immatrikulation

Studienziele

Studienorganisation

Studieninhalte

Praktika

Prüfungen

Studiendauer

Berufe der Absolventen

Hinweis
Diplôme

Niveau requis

Conditions

d'admission

Dates de dépot des candidatures

Inscription

Objectif des études

Organisation des études

Contenu de la formation

Stages

Modalités d'évaluation

Durée des études

Professions des diplômés

Notes 